\title{
Ege Denizi’nde Yetki Alanları Paylaşımının Öncülü: Karasuları Sorunu
}

\section{The Premise of Delimitation Maritime Zones in the Aegean Sea: The Problem of Territorial Waters}

\author{
Kenan ŞAHIN*
}

$\ddot{O} z$

Makalede, karşllkkl önyargllarla biçimlenen Türkiye-Yunanistan ilişkileri çerçevesinde Ege Denizi'nde deniz yetki alanlarmn paylaşımıyla ilişkili karasular sorunu uluslararası hukuk bağlamında incelenmektedir. Bu çerçevede Ege Denizi'nde karasularn anlaşmazlğ̆nn ikili ilişkilerde kıta sahanlğ̆ başta olmak üzere diğer sorunlan $d a$ etkileyen merkezi niteliğine dikkat çekilmektedir. $B u$ varsaynm doğrultusunda Yunanistan'ın karasular üzerinden Türkiye'nin deniz yetki alanın daraltarak sadece Ege'de değil, Doğu Akdeniz de dâhil olmak üzere uluslararası hukukun Türkiye'ye tanıdığ denizin altndaki enerji kaynaklarna erişim hakkın kısttlamak gibi bir strateji izlediği ileri sürülmektedir. Makalede öncelikle, karasular hakkındaki uluslararası hukuk kurallar üzerinde durulacaktrr. Daha sonra sorunun tarihsel geçmişine yer verilerek taraflarn uluslararası platformlarda konu hakkinda öne sürdüğ̈̈ hukuki ve siyasi tezler masaya yattrilacaktrr.

Anahtar Kelimeler: Ege Denizi, Deniz Hukuku, Karasular, Türk Tezleri, Yunan Tezleri.

\section{Abstract}

In this article, the territorial waters problem, which is associated with the delimitation of maritime jurisdiction areas in the Aegean Sea within the framework of the Turkey-Greece relation formed with mutual prejudices, is examined in the context of international law. In this context, attention is drawn to the central attribute of the territorial waters conflict in the Aegean Sea, which affects other issues, especially the continental shelf in bilateral relations. In line with this assumption, it is argued that Greece follows a

* Dr. Öğretim Üyesi, Millî Savunma Üniversitesi, Deniz Harp Okulu, Beşerî ve Sosyal Bilimler Bölümü, Tuzla, İstanbul, Türkiye ORCID: 0000-0001-7404-6608, e-posta: ksahin@dho.edu.tr.

Geliş Tarihi / Submitted: 17.06.2019

Kabul Tarihi / Accepted: 25.10.2020 
strategy of narrowing Turkey's maritime zones over its territorial waters to restrict the right of access to energy resources under the sea, which is recognized by international law to Turkey not only in the Aegean but also in the Eastern Mediterranean. In this article, firstly, the rules of international law about territorial waters will be examined. Then, the historical background of the problem will be debated, and the legal and political arguments put forward by the parties on the international platforms will be discussed.

Keywords: Aegean Sea, Law of the Sea, Territorial Waters, Turkish Theses, Greek Theses.

\section{Giriş}

Türkiye ile Yunanistan arasındaki sorunlar her ne kadar daha eskiye dayansa da 1970'li yılların ortalarından itibaren Ege Denizi'nde gelişen çok yönlü anlaşmazlıklar ${ }^{1}$ iki devlet arasındaki ilişkilere yön vermeye devam etmektedir. Anlaşmazlıklar arasında tarafların Ege Denizi'nde karasuları genişliğinin ne kadar olacağı tarihsel ve hukuksal çerçevedeki temel sorunlardan biridir. İkinci Dünya Savaşı sonrası uluslararası deniz hukukundaki gelişmelerle Yunanistan, karasularını 12 deniz mili² kadar genişletmeye hakkı olduğu iddiasını öne çıkarmıştır. Buna karşılık Türkiye, egemenlik hakları bağlamında deniz yollarını kısıtlayacağı gerekçesiyle bu girişimi bir savaş nedeni (casus belli) olarak kabul edeceğini birkaç kez dile getirilmiştir. Yunanistanlı siyasi liderlerin çeşitli aralıklarla Ege Denizi'nde karasularını mevcut uygulama olan 6 deniz mili üzerine çıkaracaklarını açıklamaları $^{3}$ bu hedeften vazgeçilmediğini göstermektedir. Türkiye'deki

${ }^{1}$ Yunanistan, Ege'de sadece kıta sahanlığı sorununu tartışılması gereken bir sorun olduğunu kabul etmesine karşın başka sorunlar da vardır. Ege Denizi'nde iki devlet arasındaki sorunlar ana hatlarıyla şu başlıklarla sıralanabilir: karasuların genişliği, kıta sahanlığının sınırlandırılması, ulusal hava sahalarının sınırlandırılması, askerî uçuş faaliyetlerinin kontrolü, adacık ve kayacıkların mülkiyeti, Doğu Ege adalarının askersizleștirilmesi. Bu sorunların detayları için bkz. Yüksel İnan ve Yücel Acer, "The Aegean Disputes", Foreign Policy Institute, Ankara, 2003, s. 1-51.

${ }^{2}$ Uluslararası hukuka göre 1 deniz mili 1852 metre olarak kabul edilmektedir.

${ }^{3}$ Nitekim Kasım 2018'de dönemin Yunanistan Başbakanı Aleksis Çipras, Ege'de Yunan karasularını kademeli olarak 6 milden 12 mile çıkarılacağını belirtmiştir. Çipras, sorunun dağınık olarak değerlendirildiği ile konunun yeni bir gelişme olmadiğını belirterek Yunanistan'ın Ege'de haklarını kullanacağını vurgulamıștır. Ac̣ıklama için bkz. "Yunanistan Başbakanı Çipras: Karasularımızı 6 milden 12 mile çıkaracağız", https://tr.euronews.com/2018/11/09/yunanistan-basbakan-cipras-karasularimizi-6-milden -12-mile-cikaracagiz (Erişim Tarihi: 16.05.2020). 
karar vericiler ise bu girişime müsaade etmeyecekleri ve sorunun adil temelde çözülmesi gerektiği yönündeki söylemlerini aynı şekilde sürdürmektedir.

Ege Denizi'nde yetki alanlarıla ilgili sorunlar, her iki devletin deniz sınırlarını şimdiye kadar herhangi bir anlaşmayla belirleyememesinin bir sonucudur. Konu hakkındaki politik çekişmeler Türkiye ve Yunanistan arasında tekrarlayan krizler üretmekte; özellikle enerji, jeopolitik ve uluslararası hukuk denklemlerinde bölgeyle ilgilenen küresel ve bölgesel güçlerle kurulan ilişkileri etkilemektedir. Konuyu berraklaştırmak amacıyla ilkin, uluslararası hukuk metinlerinde yer alan karasuların genişliği, hukuki rejimi ve sınırlandırılmasıyla ilgili kuralların uygulanış biçimleri irdelenecektir. İkinci olarak, Türkiye ve Yunanistan'ın soruna yaklaşımı çerçevesinde izledikleri dış siyaset ve argümanları doğrultusunda birbirlerine karşı verdikleri yanıtlar üzerinde durulacaktır. Çalışmada, Ege'de karasuları sorununun, Yunanistan'ın Türkiye'nin kıyıdaş olduğu deniz alanları üzerindeki yetkilerinin daraltılmasının başlangıcı/temeli olmasıyla birlikte hem Ege'de hem de Doğu Akdeniz'de uluslararası hukukun Türkiye'ye tanıdığı denizdeki kaynaklara erişim hakkını sınırlandırmak gibi bir stratejinin ana kaynağı olduğunu göstermek hedeflenmektedir.

\section{Uluslararası Hukuk Açısından Karasuları}

\subsection{Karasulamnın Genişliği ve Hukuki Rejimi}

Teamüllerin önemli olduğu uluslararası hukuka göre bir devlet ülkesi, büyüklüğü fark etmeksizin genellikle kara, deniz ve havadan müteşekkildir. Devlet ülkesinin bölümlerinden olan deniz, uluslararası hukukta açı ve devletlerin egemenliğine tabi olmak üzere iki farklı hukuki rejime ayrılmaktadır. Denizler, bu bağlamda kıyıda bulunan devletlerin haklarına göre sınıflandırılmaya tabi tutulurlar. Devlet ülkesinin deniz yetki alanlarından birini oluşturan karasuları, "bir kıyı devletinin kara ülkesini çeoreleyen ve uluslararası hukuka uygun olarak açıklara doğru belirli bir genişliğe kadar uzanan kıyı devletine ait deniz kuşağına verilen addır."4 Dolayısıly karasulardan bahsedildiğinde bir devletin sahilleri ile açık deniz sahilleri arasında kalan bölge ile buradaki deniz tabanı, yer altı ve üzerindeki hava sahası kastedilmektedir. Karasuları, bir devletin kara toprakları gibi aynı

\footnotetext{
${ }^{4}$ Hüseyin Pazarcı, Uluslararası Hukuk, Turhan Kitabevi, Ankara, 2009, s. 258.
} 
yetkileri kullandığı ve egemen oldukları ülke parçalarıdır. ${ }^{5} \mathrm{Bu}$ açıdan devletlerin kara ülkesinde kullandığı yetkilerin tümü karasuları için de geçerlidir. Buna karşılık söz konusu yetkiler iki unsurla birlikte değerlendirilmelidir. Bunlardan ilki, yabancı ticaret gemilerin kııı devletinin barışına, güvenliğine ve ekonomik düzenine zarar vermemek şartıyla kesintisiz ve hızlı biçimde yapacakları zararsız geçiş hakkıdır. ${ }^{6}$ Diğeriyse kıyı devletinin yargısal yetkisi (kıta sahanlığı ve münhasır ekonomik bölge) doğrultusunda alacağı tedbirlerdir.

Devletlerin kıyıdan denizlere doğru egemen olabileceği alanın genişliğinin ne kadar olacağı tartışmaları yeni değildir. Modern anlamda yetkinin nereye kadar uzandığ ilk kez 17 . yüzyılda devletlerin ilgi alanına girmiştir. ${ }^{7}$ 17. ve 18. yüzy1lda "kara egemenliği silah gücünün sona erdiği yerde biter" anlayışı büyük ölçüde yerleşik bir uygulama niteliği kazanmıştır. ${ }^{8}$ Top menzilinin o dönemde en çok 3 deniz mili olması, devletlerin bu sınırlamayı geçerli kabul etmelerine yol açmıştır. ${ }^{9} \mathrm{Ne}$ var ki ilerleyen yüzyıllarda silah teknolojisindeki gelişmeler ile denizlerdeki ekonomik etkinliklerin daha önemli hale gelmesiyle "top atışı kuralı" olarak da bilinen 3 deniz mili ölçütü genel-geçer bir kural olmaktan çıkacaktır. Bu gelişmelere bağlı olarak devletler, güvenliği sağlamak, deniz ve toprak altındaki kaynakları kullanmak için denizlerdeki egemenliklerini sürekli genişletme gereği duyacaklardır.

\footnotetext{
${ }^{5}$ Karasularının hukuki rejimi, kıyı devletinin buradaki hak ve yetkileri ile üçüncü devletler lehine getirilen sinırlamaları anlatmaktadır. Selami Kuran, , 3. Baskı, Türkmen Kitapevi, İstanbul, 2009, s. 81.

${ }^{6}$ Zararsız geçiş hakkı çerçevesinde oluşan normların değerlendirilmesi için bkz. Hüseyin Pazarc1, a.g.e., s. 261-265, Selami Kuran, a.g.e., s. 82-86.

${ }^{7} 1609$ 'da Hugo Grotius, Mare Liberium adlı eserinde denizlerin serbestliğini vurgularken kıyıda bulunan devletlerin katı egemenliğini içeren deniz alanının varlığından söz etmiştir. Denizin herkesçe sınırlanmadan özgürce kullanımı konusunda Grotius ile benzer şekilde düşünen Cornelius Van Bijnkershoek, 1702'de yayınladığı De Dominio Maris Dissertatio adlı eserinde kıyı devletlerinin egemenlik haklarının tanınması gerektiğine dikkat çekmiştir. Nico Schrijver, Sovereignty Over Natural Resources: Balancing Rights and Duties, Cambridge, Cambridge University Press, 2008, s. 203.

${ }^{8}$ Sevin Toluner, Milletlerarası Hukuk Dersleri, İstanbul, Beta Basım Yayın, 1996, s. 56.

9 Aydoğan Özman, "Ege'de Karasuları Sorunu”, Ankara Üniversitesi Siyasal Bilgiler Fakültesi Dergisi, Cilt 63, No. 3-4 (Temmuz-Aralık 1988), s. 174.
} 
Karasuların genişliğinin ve sınırının tespitinde esas ilerlemeler 20. yüzyıl ortalarında yapılan deniz hukuku konferanslarıyla gerçekleşmiştir. ${ }^{10}$ 1958 yılında Cenevre'de toplanan Birinci Deniz Hukuku Konferansı'nda karasularının genişliği konusu uzun tartışmalara neden olmuştur. Ancak devletler arasında çatışan ulusal çıkarlar nedeniyle sözleşmeye bu konuyla ilgili herhangi bir hüküm koyulamamıştır. ${ }^{11} 1960$ yılında yine Cenevre'de karasularının genişliği gibi toplanma nedenine uygun İkinci Deniz Hukuku Konferansı'nda da uzlaşı sağlanamamıştır. ${ }^{12}$ Nihayet 1973'te başlayıp 1982'de sonuçlanan Üçüncü Deniz Hukuku Konferansı'nda konu yeniden ele alınarak kıyıdaş devletlerin karasularını azami genişletebilecekleri bir sınır kararlaştırılmıştır. Birleşmiş Milletler Deniz Hukuku Sözleşmesi (BMDHS) ${ }^{13}$ 3. maddesinde yer alacak bu karar, devletlerin karasuların 12 deniz milini geçmeyecek biçimde bir sınırı tespit edeceklerini belirtmektedir. ${ }^{14}$

Karasuları sınırının azami 12 mil kuralı çerçevesinde uygulanması, sözleşmede yer alan diğer madde ve koşullarla birlikte değerlendirilmelidir. Nitekim BMDHS'nin 15. maddesinde taraflar arasında anlaşma olmadığ 1 zaman, haklar ya da öteki özel durumlar başka türlü bir sınırlandırma gerektirmiyorsa karasuları sınırlandırılması eşit uzaklık yöntemine göre yapılacağ 1 belirtilmektedir. ${ }^{15}$ Dolayısıyla karasularıyla ilgili 15 . maddede özel koşullar dışında, bir kıyı devletinin kıyılar arasındaki eşit uzaklık çizgisinden öteye geçme hakkının bulunmadığı vurgulanır. Dahası teamüller haline gelen birçok maddede Uluslararası Adalet Divanı Statüsü'nün

${ }^{10}$ BM deniz hukuku konferansları için bkz. Şule Anlar Güneş, "Birleşmiş.. Milletler Deniz Hukuku Sözleşmesi ve Deniz Çevresinin Korunması", Ankara Üniversitesi Hukuk Fakültesi Dergisi, 2007, Cilt 56, Say1 2, s. 5-10.

${ }^{11}$ Selami Kuran, age, s. 73. Tayyar Arı, "Ege Sorunu ve Türk-Yunan İlişkileri: Son Gelişmeler Issı̆̆ında Karasuları ve Hava Sahası Sorunları", Ankara Üniversitesi Siyasal Bilgiler Fakültesi Dergisi: Prof. Dr. Latif Çakıcıya Armağan”, 1995, Cilt 50, No.1-2 (OcakHaziran 1995), s. 53-54.

12 Güneş, a.g.m. s. 5.

${ }^{13}$ Sözleşmeyle ilgili maddelerin içeriklerine ilişkin veriler, çalışmanın bundan sonraki bölümlerinde şu kaynaktan aktarılacaktır: The Law of The Sea: Official Text of the United Nations Convention on the Law of the Sea with Annexes and Index, United Nations, New York, 1983.

${ }^{14} 16$ Kasım 1994'te yürürlüğe giren BMDHS'nin 3. maddesinde "Her devlet karasularının genişliğini tespit etme hakkına sahiptir; bu genişlik işbu sözleşmeye göre tespit edilen esas hatlardan itibaren 12 deniz milini geçemez." ifadesi yer almaktadır.

${ }^{15}$ Hüseyin Pazarc1, a.g.e., s. 260-261. 
38. maddesinde belirtildiği şekilde düzenlemelerin uluslararası hukuka uygun olarak anlaşma ile yapılacağı ifadesi yer almaktadır. Yine bu konulardaki düzenlemelerin aynı sözleşmenin 300. maddesinde yer alan "iyi niyet" ve "hakkın kötüye kullanılmaması ilkeleri” göz önünde bulundurularak gerçekleştirilmesi önem arz etmektedir. Tüm bunlar karasularının genişliği ve rejimini belirlemede "hakkaniyet" ölçütleri doğrultusunda belirlenmesinin makul ve birçok unsuru gözeterek hukuka uygun biçimde yapılması gerektiğini göstermektedir.

\subsection{Karasularin Sintrlandirnlmast}

Coğrafi konumları birbirine yakın olan ülkeler arasında karasularının genişliğinin tespit edilmesi ve diğer sahildar devletlerin egemenlik hakları karşısında belirli bir sınırlama (delimitation) ihtiyacı olduğu açıktır. $\mathrm{Bu}$ çerçevede zamanla karasuların genişliği üzerinde sınırlama belirlemeye yarayan iç, dış ve yan sınır belirleme yöntemleri gelişmiştir. ${ }^{16}$ Karasularının kıyının hangi kısmından başlayacağını gösteren iç sınırının tespitinde "esas hat" adı verilen bir çizginin olduğu varsayılır. Buradan yola çıkarak iki yöntemle iç sınırlar tespit edilebilmektedir. BMDHS 5. maddesine göre karasularının iç sınırı, kıyının düz görünümlü olduğu durumlarda sahil boyunca uzanan suların en çok çekildiği alana, yani en düşük cezir hattına "normal esas hatlar" çizilir. Körfez ya da kıyının yakınında adalar, adacıklar, kayalıklar veya sığlıklar bulunuyor ve/veya kıyı derin bir şekilde girintili çıkıntılı durum arz ediyorsa, bunların en dış noktaları arasında "düz esas hatlar" çizilir. ${ }^{17}$ Böylece karasuları esas hattının berisinde kalan sular, devletin iç sularına dâhildir. ${ }^{18}$

Karasuların nerede bittiğini gösteren dış sınırı ise BMDHS 4. maddesine göre her noktası esas hattın en yakın noktasından karasularının genişliğine eşit uzaklıkta bulunan hattan oluşmaktadır. Bir devletin karasularının dış sınırlarının saptanmasında esas çizgiden hareket ederek

\footnotetext{
${ }^{16}$ Selami Kuran, a.g.e., s. 60.

${ }^{17}$ Buna göre körfezler, limanlar, girintili çıkıntılı kayalar, kıyıya yakın takımadalar, sular çekilince beliren kayalıkları barındıran adalar, mercan adaları olan adalar, nehir ağızları kıyı çizgisinin değişken olduğu bölgelere düz esas hatlar çizilebilir. Selami Kuran, a.g.e., s. 61. 18 İç sınırın tespiti hakkında bkz. Aydoğan Özman, Deniz Hukuku I: Giriş, Kaynaklar, Kişiler, Nesneler, Ulusal Alanlar, Turhan Kitabevi, Ankara, 2006, s. 301; Selami Kuran, a.g.e., s. 60-61.
} 
üç değişik yöntem kullanabilmektedir. ${ }^{19}$ Buna göre birinci yöntem, kıyı çizgisine tam paralel olarak kabul edilen genişlikte dış sınır çizmektir. İkinci yöntem, esas çizgi üzerindeki kimi noktalardan yaylar çizerek bunların kesiştiği noktaları birleştiren çizgiyi dış sınır olarak kabul etmektedir. Üçüncü yöntemse, kıyı üzerindeki çıkıntı noktalarını düz çizgilerle birleştirip bu çizgiye paralel kabul edilen karasuları genişliğinde, düz çizgiler çizmektir. Bu durumda karasuyu genişletildiği zaman onunla birlikte kıta sahanlığı ve hava sahası da genişlemektedir.

Birbirine komşu, kıyıdaş/sınırdaş devletlerin karasularının yan sınırının belirlenmesinde ise eğer taraflar arasında bir anlaşma yoksa uygulamada beş yöntemden söz edilebilir. Bunlardan birincisi, kara ülkesi sınırını açık denize doğru, karasularının dış sınırına uzatmaktır; ikincisi, kara sınırının denize ulaştığı noktada kıyıya bir dikey çizerek; üçüncüsü, kara sınırının denize ulaştığı noktadan sahilin genel yönüne dikey bir çizgi çizerek; dördüncüsü, kara sınırının sahile ulaştığı noktadaki enlem veya boylam çizgileri esas alınarak; sonuncusu, her iki devletin esas çizgilerinin en yakın noktalarına eşit uzaklıkta ve açıda çizgiler çizerek bu çizgilerin kesiştiği noktaların birleştirilmesiyle mümkün olabilmektedir. ${ }^{20}$

Kıyıya sahip devletlerin kendiliğinden ve münhasıran yetki sahibi olduğu karasularının sınırlandırılması ve hukuki rejimi üzerine buraya kadar sözü edilen sınır tespit usulleri, uluslararası hukukta deniz alanlarının kesişme ya da birleşme durumlarıyla birlikte yakınlığı veya karşıtlığına göre farklılaşmaktadır. BMDHS'nin 3. maddesinde anılan 12 mil kuralı ancak "zararsız geçiş hakkı" ile "yarg1 yetkisi ve bağışıklığı" gibi iki temel uluslararası hukuk kuralı çerçevesinde geçerlidir. Buna karşın özel durumlardan ötürü uluslararası hukukun kurallarından sapmamak şartıyla tarafların egemenlik haklarını kısıtlayıcı bir sonuç doğurmayacak biçimde söz konusu sınırların kendi aralarında anlaşmayla belirlenmesinin ilk seçenek olarak düşünülmesi gereklidir. Aksi durumda tek taraflı girişilen eylemlerin orantısız ve adil olmayan bir paylaşım sonuçları üretmesi kaçınılmazdır.

\footnotetext{
${ }^{19}$ Karasularının dış sınırın tespiti hakkında bkz. Aydoğan Özman, a.g.e., s. 301-306.

${ }^{20}$ Aydoğan Özman, a.g.e., s. 307-308.
} 


\section{Uluslararası Politikada Ege Denizi'nde Karasuları Sorunu}

\subsection{Feopolitik Unsur: Ege Denizi'nin Konumu ve Önemi}

Karasuları konusunda şimdiye kadar uygulanan teamüller ve yukarıda değinilen hukuk kuralları açısından Ege Denizi ${ }^{21}$ özgün bir yapı sunmaktadır. Söz konusu deniz, bulunduğu coğrafya itibariyle Akdeniz'in Anadolu ve Balkan yarımadaları arasında devam eden koludur. Saroz Körfezinden güneydeki Girit Adasına kadar uzanan Ege Denizi, kuzeyden güneye yaklaşı $380 \mathrm{mil}(612 \mathrm{~km})$ uzunluğa sahip olmakla birlikte $186 \mathrm{mil}$ $(299 \mathrm{~km})$ genişliğinde, toplam alan 183.000 mil kare $(215.000 \mathrm{~km} 2)$ olarak hesaplanmaktadır. ${ }^{22}$ Üç kıtanın deniz, hava ve kara ulaşım yollarının birleşme noktasında bulunmakta, aynı zamanda Çanakkale Boğazı ile Marmara'ya, İstanbul Boğazı ile Karadeniz'e açılmaktadır. ${ }^{23}$ Bu nitelikleriyle Türkiye ve Yunanistan arasında deniz ve hava faaliyetlerinin çok yakından gerçekleştirildiği bir bölgeyi oluşturmaktadır.

Ege Denizi, Yunanistan kıyılarıyla Türkiye kıyıları arasında bulunan irili ufaklı iki bin üzerinde ada ve ada görünümündeki kara parçalarını da içine alan yarı kapalı deniz (semi-enclosed sea) niteliği göstermektedir. ${ }^{24}$ BMDHS 122. maddesine göre kapalı veya yarı kapalı denizden, iki veya daha fazla devlet tarafından çevrili ve dar bir geçitle başka bir denize veya okyanusa bağlanan veyahut tamamen ya da kısmen iki veya daha fazla kıyı devletinin karasuları ile münhasır ekonomik bölgelerinden oluşan bir körfez,

\footnotetext{
${ }^{21}$ Ege Denizi isminin nasıl doğduğuna ilişkin farklı anlatılar bulunmaktadır. Ege adının antik çağlara kadar gittiği bir mitolojik anlatıya göre, Ege'nin oğlunu yitirdiğini zannederek kendini denize atan Kral Aegeus'un adından türediği iddia edilir. Batı dillerinde, ada bakımından zengin bir denizi ve aynı zamanda takımadaları ifade eden Arcipelago şekline dönüşmesinden türediği de iddialar arasındadır. Ege Denizi isminin adlandırması için bkz. Paola Ceccarelli, "Naming the Aegean Sea”, Mediterranean Historical Review, 2012, Vol. 27, No. 1 (June 2012), s. 25-49. "Ege" ismi 1940'lı yıllara kadar kullanılmayacak burası için ya Akdeniz (Bahr-i Seyid) ya da adaların sayıları çok fazla olduğundan "Adalar Denizi” (Cezayir-i Seyid) denilecektir.

22 “Aegean Sea”, https://www.britannica.com/place/Aegean-Sea (Erişim Tarihi: 07.05.2020). Ege Denizi'nin coğrafi özellikleri hakkında daha geniş bilgi için bkz. Ali Kurumahmut, Ege'de Temel Sorun: Egemenliği Tartışmalı Adalar, Türk Tarih Kurumu, Ankara, 1998, s. 1-3.

${ }^{23}$ Cemalettin Taşkıran, Oniki Adanın Dünü ve Bugünü, Genel Kurmay ATASE Yayınları 1996, s. 1.

${ }^{24}$ Ege'nin yarı kapalı deniz özelliği hakkında bkz. Sertaç Hami Başeren, Ege Sorunları, 2. Baskı, Türk Deniz Araştırmaları Vakfı Yayınları, Ankara, 2006, s. 10-14.
} 
havza veya deniz anlaşılmaktadır. Aynı sözleşmenin takip eden 123. maddesinde, kapalı veya yarı kapalı bir denize sahildar olan devletlerin sözleşme gereğince kendilerine ait hakların kullanılması ile yükümlülüklerin yerine getirilmesinde aralarında iş birliğinde bulunmaları tavsiye edilmektedir. Dolayısıyla burada sayılan niteliklere yakın Ege Denizi hem uluslararası hukuk açısından hem de dünyadaki diğer denizlere kıyasla kendi içerisinde değerlendirilmesi gereken durum sunmaktadır.

Genellikle jeopolitik analizlerde Ege Denizi'nin, Türk boğazlarını, Süveyş Kanalını ve Doğu Akdeniz’i kontrol altında tutabilmek açısından önemli bir imkâna sahip olduğu vurgulanır. Daha geniş bakıldığında Doğu Akdeniz üzerindeki enerji denklemi üzerinden bölgenin bir güç ve hâkimiyet mücadelesi alanı olma gibi bir potansiyeli de bulunmaktadır. Ege Denizi, bulunduğu coğrafyanın güvenliği meselesi bakımından da önemlidir. Güvenlik riskleri üzerinden değerlendirildiğinde Anadolu istikametinde icra edilecek bir harekâtta önemli ikmal, kara, deniz ve hava üssü ile Anadolu'ya atlama merkezlerini oluşturacak harekâtın desteklenmesi açısından kritiktir. Dolayısıyla üstünlük mücadelesi, savunma konusundaki bölgenin sunduğu coğrafi derinlikle ilişkilidir. Çünkü Ege Denizi'ne herhangi bir istikametten yapılacak harekâta karşı deniz harekâtına kısıtlamalar getirebilmektedir. Sonuçta her iki devlet açısından bölgedeki hukuksal ve siyasal tartışmaların arka planında Ege'nin sayılan özellikleri bir şekilde etkili olan faktörleri oluşturmaktadır.

\subsection{Türkiye ve Yunanistan İlişkileri Çerçevesinde Karasular Sorununun Arka Planı}

NATO üyesi Türkiye ve Yunanistan arasında Soğuk Savaş koşullarının yaşandığı 1970'li yıllardan itibaren Kıbrıs ekseninde yaşanan gelişmelerle tırmanan Ege Denizi karasuları sorununun evveliyatı daha gerilere uzanmaktadır. Nitekim karasuları başta olmak üzere Ege Denizi'nde yaşanan sorunlar iki devlet arasında tarihsel ilişkilerde ortaya çıkan çekişmelere dayanmaktadır. ${ }^{25}$ Tarafların birbirlerine karşı duyduğu

${ }^{25}$ Nitekim İnalcık, Türkiye ve Yunanistan arasında Ege sorununun temellerinin 19. yüzyıldan itibaren Osmanlı içerisindeki Hıristiyan tebaa içerisindeki Yunanistan'ın bağımsız bir devlet kurmasını takibinde yaşanan gelişmelerde ilişkilendirmekte, Helenizmin değişmez hedefi olarak nitelediği "Megali İdea" çerçevesinde meselenin 
güvensizlik, önyargı ve milliyetçilik temelli karşıtlıklar, birbirini tetikleyen sorunları derinleştirmektedir. ${ }^{26} 1923$ yılında imzalanan Lausanne Antlaşması'nda Ege Denizi'nde karasuları genişliği Türkiye'ye yakın adaların konumları göz önüne alınarak 3 mil olarak uygulanmaya başlamıştır. Montreux Boğazlar Sözleşmesi'ni takiben 17 Eylül 1936 tarihinde Yunanistan parlamentosu kabul ettiği 230 sayılı kanunla karasuları genişliğini tek taraflı olarak 6 mile yükseltmiştir. Bu dönemde ikili ilişkilerde nispeten dostane bir ortam olmasının yanında İtalya'nın Akdeniz'de artan tehdidi nedeniyle Yunanistan'ın girişimlerine Türkiye'den itiraz gelmemiştir. ${ }^{27}$ Yunanistan, tedricen Ege Denizi'nde tek taraflı olarak karasularını genişletirken; yaklaşık otuz yıllık bir süre daha Türkiye, bölgenin istikrarını etkilemediğinden olsa gerek kendi karasularını genişletme yoluna gitmemiştir.

1960'lı yılların ilk yarısında Türkiye'nin de garantör olduğu Kıbrıs Cumhuriyeti içindeki Kıbrıslı Türkler ve Rumlar arasındaki ilişkilerin bozulması, Türkiye'nin Ege'deki karasularının genişliği konusunda tutum değişikliğine sevk etmiştir. Bu çerçevede 15 Mayıs 1964 tarihinde kabul edilen 476 sayılı Karasuları Kanunu'nun ilk maddesiyle Türkiye karasuları genişliğinin 6 mil olduğu tespit edilmiş, sonraki maddesinde karasuları daha geniş devletlere karşı mütekabiliyetin esas alınacağı vurgulanmıştır. ${ }^{28}$ Böylece Lausanne ile sabitleştirilen 3 millik sınır, bu kanun ile tarafların karşılıklı olarak Ege Denizi'nde 6 mil karasuyu genişliği olarak yeni bir statükoyu doğurmuştur. Kıbrıs'taki gelişmeler ilerleyen ikili ilişkilere yön verirken artık Ege'de karasuları ile ona bağlı olarak gelişen diğer sorunlar iki ülke için de ulusal güvenlik meselesine dönüşmüştür.

analiz edilmesi gerektiğini belirtmektedir. Halil İnalcık, "Helenizm, Megali İdea ve Türkiye”, Doğu Batı, 2005, Say1 31 (Şubat, Mart, Nisan 2005), s. 9-26.

${ }^{26}$ Türkiye ve Yunanistan arasında karşılıklı güvensizlik temelinde ortaya çıkan politik sorunların nedenleri ile bu sorunların çözümüne yönelik önerileri içeren çeşitli çalışmalar yapılmıştır. Ayrıca tarihsel süreçte Yunanistan ve Türkiye'nin birbirilerine yönelik milliyetçi tahayyül ve söylemlerini analiz eden karşılaştırmalı bir çalışma için bkz. Umut Özkırımlı ve Sypros A. Sofos, Tarihin Cenderesinde Yunanistan ve Türkiye'de Milliyetçilik, İstanbul Bilgi Üniversitesi Yayınları, İstanbul, 2013.

27 Lozan dengesini bozan bu düzenleme Atatürk ve Venizelous'un şahsi dostluk ilişkilerindeki koşullar altında gerçekleşmiştir. Aydoğan Özman, a.g.e, s. 176-177.

${ }^{28}$ Kanun için bkz. https://www.tbmm.gov.tr/tutanaklar/KANUNLAR_KARARLAR/kan untbmmc047/kanuntbmmc047/kanuntbmmc04700476.pdf, (Erişim Tarihi:18.05.2020). 
1970’li yılların başlarında Üçüncü Deniz Hukuku Konferansı'nda karasuların genişliği hakkında yapılan görüşmeler, Yunanistan'ın, Ege'de karasularını 12 mile çıkaracağı yönünde açıklanmalarına yol açmıştır. Bunun üzerine Türkiye, Haziran 1974'te verdiği notada Ege'nin kendine özgü (sui generis) durumuna dikkat çekip Türkiye'nin açık denize çıkışını engelleyecek bir genel kuralı kabul etmeyeceğini açıklamıştır. Bu arada Türkiye'nin 1973 yllında daha önce Yunanistan'ın yaptığı gibi Ege Denizi'nde sondaj ve petrol arama yetkisinin kullanılmaya başlanması üzerine Yunanistan meseleyi BM Güvenlik Konseyi ve Uluslararası Adalet Divanı'na taşımıştır. BM Güvenlik Konseyi, aldığ 395 sayılı karar ile taraflar arasında barışçl görüşmelerin yapılmasını salık verirken; daha sonra Divan, yetkisizlik gerekçesiyle Yunanistan'ın isteği konusunda bir hükme varmamıştır. Bunlar üzerine Yunanistan'ın tutum değişikliği gerçekleşmiş, kıta sahanlığı meselesi de dâhil olmak üzere taraflar arasında gelişen güvensizlik ortamı, ancak Kasım 1976'da Ioannis Tzounis ve M. Suat Bilge tarafından imzalan Bern Deklarasyonu ile aşılabilmiştir. ${ }^{29}$ Burada taraflar karş1lıklı olarak arama faaliyetleri hakkında birbirlerini bilgilendirme ve Ege Denizi'ndeki statükoya saygı gösterme sözü vermişlerdir. ${ }^{30}$

Üçüncü Deniz Hukuku Konferansı'ndaki müzakerelerde aktif biçimde yer alsa da çekincelerini belirtip sözleşmeyi imzalamayan Türkiye, 20 Mayıs 1982'de kabul edeceği 2674 sayılı Karasuları Kanunu ile Ege'de karasuların genişliğinin 6 deniz mili olduğunu teyit etmiştir. ${ }^{31}$ Daha önce kabul edilen 476 sayıl kanunu ortadan kaldıran bu yeni kanunun 1. maddenin son fikrasında, Bakanlar Kurulu'nun ${ }^{32}$ belirli denizlerde, o denizlerle ilgili bütün özellikleri göz önünde bulundurmak ve hakkaniyet ilkesine uygun olmak şartıyla, 6 deniz milinin üzerinde karasuları genişliği tespit etmeye yetkilidir ifadesi yer almıştır. Bu durum Akdeniz ve Karadeniz dışında 12 mil

29 Alexis Heraclides, "The Unresolved Aegean Dispute: Problems and Prospects" Alexis Heraclides and Gizem Alioğlu Çakmak (Eds.), Greece and Turkey in Conflict and Cooperation, Routledge, London and New York, 2019, s. 91-92.

${ }^{30}$ Serdar Ş. Güner, “Aegean Territorial Waters Conflict: An Evolutionary Narrative”, Conflict Management and Peace Science, 2004, Vol. 21, No. 4 (September 2004), s. 300.

31 Kanun için bkz. http://www.mevzuat.gov.tr/MevzuatMetin/1.5.2674.pdf (Erişim Tarihi: 18.05.2020).

${ }^{32}$ Daha sonra 698 sayılı Kanun Hükmünde Kararname ile "Bakanlar Kurulu” ibaresi Cumhurbaşkanı olarak değiştirilecektir. 
kuralının Ege Denizi'nde kabul edilemeyeceğini işaret etmektedir. Düzenlemenin bu şekilde yapılması, aşağıda Türkiye'nin konu hakkındaki tezlerinde de görüleceği üzere yine Ege Denizi'nin kendine özgü coğrafi durumuna dayandırılmıştır.

Kıbrıs Barış Harekâtı sonrası 1976 ile 1981 arasında taraflar bir şekilde uzlaşma arayışları içerisinde olurken Yunanistan'da 1981 yılında Andreas Papendrau'nun iktidarı devralmasıyla görüşmeler kesintiye uğramıştır. ${ }^{33}$ 1981 yılında Yunanistan, Bern Deklarasyonu'na rağmen Tasos adası gibi tartışmalı bölgelerde sondaj faaliyetlerine yeniden başlaması karşısında Türkiye'nin de aynı şekilde petrol arama faaliyetlerine başlayacağını bildirmesiyle oluşan kriz, 1982 yılında kurulan diyalog ile aşılmıştır. ${ }^{34} \mathrm{Bir}$ süre daha Bern Deklarasyonu'ndaki ilkelere geri dönülürken Yunanistan'ın 1985 ve 1987 yılları arasında sondaj faaliyetlerine devam edeceğini açıklaması, ilişkileri 1976'daki krize benzer şekilde bir kez daha germiştir. Davos Zirvesi'ne katılan Mayıs ve Eylül 1988'de tarafların o dönemki Dışişleri Bakanları Mesut Yılmaz ile Karalos Papoulias, Atina ve İstanbul mutabakatlarını imzalamışlardır. Mutabakatlar temelde birbirilerinin egemenliklerine sayg1 duymak yanında denizlerde beklenmeyen kaza ve çatışmalara karşı ön alıcı "güven artırıcı önlemleri" içermiştir. ${ }^{35}$

Öte yandan, 1990'lı yılların ilk yarısı Türkiye ve Yunanistan ilişkileri bakımından pek uzlaşmacı sonuçlar üretmemiştir. Kasım 1994'te yürürlüğe giren BMDHS'nin Mayis 1995'te Yunan Parlamentosu'nda onaylamas1 sonrası Yunanistan, Ege'de 12 deniz mil karasuları hakkının saklı olduğu yönünde bir kanun çıkarmıştır. Buna cevaben 8 Haziran 1995 tarihinde Türkiye Büyük Millet Meclisi, Yunanistan'ın 12 mil hakkı kullanması ve karasularını artırması halinde askerî kuvvet kullanımı dâhil olmak üzere tüm tedbirlerin alınması yönünde daimî bir karar almıştır. 1996 yılı

\footnotetext{
${ }^{33}$ Heraclides, a.g.e., s. 93.

${ }^{34}$ S. Gülden Ayman, İyi Komşuluğun Formülü: Türk Dış Politikasında Teritoryal Sorunlar, Yalın Yayıncilık, İstanbul, 2012, s. 69.

35 Atina mutabakatı için bkz. "Memorandum of Understanding", http://www.mfa.gov.tr/site _media/html/aegean-sea-reference-documents-1.pdf (Erişim Tarihi: 18.09.2020). İstanbul mutabakatı için bkz. "Guidelines for the Prevention of Accidents and Incidents on the High Seas and International Airspace”, http://www.mfa.gov.tr/site_media/html/aegean-seareference-documents-2.pdf (Erişim Tarihi: 18.09.2020).
} 
başlarında her iki ülkenin egemenlik konusunda uzlaşamadığı için patlak veren Kardak/Imia krizi bir kez daha tarafları karşı karşıya getirmiştir. Ancak daha sonra ABD'nin girişimiyle 8 Temmuz 1997'de Madrid'deki NATO toplantısında taraflar "tek taraflı eylemlere girişmeyecekleri" ile "güç kullanma tehdidinde bulunmayacaklarını" içeren bir iyi niyet deklarasyonu yayınlamalarıyla tansiyon düşmüştür. ${ }^{36}$

1999 Helsinki Zirvesi ile Türkiye Avrupa Birliği'ne tam aday ülke statüsünü kazanırken ilişkilerin yumuşadığı bir süreçte sınır sorunlarının çözülmesini tavsiye eden zirve kararları doğrultusunda Ege Denizi'ndeki sorunların her iki tarafın da kabul edebileceği biçimde çözülmesi için diplomatik temaslar artmıştır. Bu çerçevede istikşafı görüşmeler (exploratory contacts: keşif-tetkik etmeye ilişkin) mekanizması kurulmuştur. Karasuları sorununun da tartışmalara dâhil edildiği, 12 Mart 2002 tarihinde başlayan resmî görüşmeler gizlilik esasıyla yürütülmüş; ancak somut bir sonuca ulaşmadan 2016 yılında askıya alınmıştır. ${ }^{37} 1990$ 'lı yılların sonları ile 2016 yılları arasındaki nispeten iyi ilişkilere karşın 2016 yılından itibaren Türk-Yunan ilişkilerinde Doğu Akdeniz konusu önem kazanmıştır. $\mathrm{Bu}$ sorun, taraflar arasında donanmaların da devrede olduğu seçenekler üzerinden deniz egemenliği tartışmasını artırmıştır. Doğu Akdeniz gerilimi daha sonra istikşafı görüşmelerin yeniden başlamasını gündeme getirmiş olsa da eskisinden farklı bir ortam doğmuştur. Tüm bu krizlere ve diplomatik temaslara rağmen bugün itibariyle bakıldığında taraflar arasında Ege Denizi'nde 6 mil karasuyu ötesine geçmeme statükosu devam etmekte henüz iki devletin de kabul edeceği kalıcı bir çözümden uzak fiili durum sürmektedir.

\footnotetext{
${ }^{36}$ Şule Kut, “Türk Dış Politikasında Ege Sorunu”, Faruk Sönmezoğlu (Ed.), Türk Dış Politikası Analizi, Der Yayınları, İstanbul, 2004, s. 517. Madrid'te müzakerelere çerçeve oluşturması amacıyla altı maddelik iyi niyet beyanı yayınlamıştır. Maddeler için bkz. S. Gülden Ayman, "Negotiations and Deterrence in Asymmetrical Power Situations: The Turkish-Greek Case", Mustafa Aydin and Kostas Ifantis, Turkish-Greek Relations: The Security Dilemma in the Aegean, Routledge, London and New York, 2004, s. 231.

${ }^{37}$ İstikşafı görüşmeler hakkında çözüme ulaşmayan tartışmalar için bkz. Heraclides, a.g.e., s. 93-95.
} 


\subsection{Ege'de Tarafların Karasularının Genişliğine İlişkin Tezleri ve Ortaya Çıkan Sonuçlar}

Tarihsel süreçte Türkiye ve Yunanistan'ın Ege Denizi'nde karasuları sorununa yönelik siyasal, hukuksal ve askerî olarak etkin bir strateji geliştirmeye çalıştıkları görülmektedir. Bu çerçevede konu üzerinde hem kendi mevzuatlarında ${ }^{38}$ hem de uluslararası platformlarda öne sürdükleri argümanlar birbirine zıt biçimde gelişmiştir. ${ }^{39} \mathrm{Bu}$ nedenle de karasuları sınırları konusunda yukarıda sözü edilen uluslararası hukuk kurallarının taraflarca yorumlanma biçimleri ve çözüm önerileri farklılaşmıştır. Böylece taraflar birbirini maksimalist amaçlar ve talepler ileri sürdükleri gerekçesiyle sürekli eleştirmektedir. Esasında Ege'deki sorunun BMDHS'nin kendisinden değil, uygulamadan kaynaklandığını söyleyen Oxman, çözüm arayışının tarafların hukuki konumlarından ziyade çıkarlarına odaklanması gerektiğini dile getirir. Ege'nin kendine özgü durumunun dikkate alındığı bir çözüm hem iki devletin hem de üçüncü tarafların güvenlik, ekonomik ve çevresel çıkarlarını karşılayacaktır. Buna göre BMDHS'nin “uluslararası seyrüsefere açık boğazlarda açık deniz yolları ile bir münhasır ekonomik bölgeden gelen yollar" bölümünü düzenleyen 36 . maddesinin karasularının genişliği konusunda uyarlanabilir bir seçenek olabilecektir. ${ }^{40}$

Oxman'ın sunduğu önerinin uzağında bulunan Yunanistan hem anakara hem de Ege'deki adalarının karasularının genişliği konusunda BMDHS'nin 3. maddesi uyarınca 12 milin uluslararası hukukun genel bir kuralı olduğunda ısrarcıdır. Bunun devletlerarası ilişkilerde mutlak ve devredilemez bir teamül olduğunu vurgulamaktadır. Türkiye'nin bu kuralara uyması gerektiğini belirten Yunanlılar, Ege'de karasularını 6 milde tutması

38 Türkiye ve Yunanistan'ın karasuları hakkında iç hukuklarında yaptıkları düzenlenmeler için bkz. Sertaç Hami Başeren, a.g.e., s. 111-117.

${ }^{39}$ Karasuları konusunda Türk ve Yunan tezlerini karşılaştırmalı değerlendirmeleri için şu kaynaklardan yararlanılacaktır: Alexis Heraclides, The Greek-Turkish Conflict in the Aegean: Imagined Enemies, Palgrave Macmillan, New York, 2010, s. 183-185; Ali Kurumahmut, a.g.e., s. 20-21; Melek Frrat, "Karasuları Konusunda Türk ve Yunan Tezleri Kutusu", Baskın Oran (Ed.), Türk Dış Politikası, Kurtuluş Savaşından Bugüne Olgular, Belgeler, Yorumlar, Cilt 1, 15. Baskı, İletişim Yayınları, İstanbul, 2009, s. 753.

${ }^{40}$ Bernard H. Oxman, "Applying the Law of the Sea in the Aegean Sea", Bayram Öztürk and Nesrin Algan (Eds.), Proceedings of the International Symposium on the Problems of Regional Seas (Turkish Marine Research Foundation-TÜDAV, İstanbulTurkey, 12-14 May 2001), ss. 266-80. 
12 milden vazgeçtiği anlamına gelmediğini dile getirirler. Yunanistan, $12 \mathrm{mil}$ uygulamasına geçildiği takdirde Türkiye'yi Ege'de kısıtlayacağı argümanını kabul etmemekte, Türk gemileri buradan zararsız geçiş hakkından yararlanabileceğini savunmaktadır. Yunan nüfusunun büyük bir bölümünün Ege kıyı ve adaları veya buralara yakın bölgelerde yaşaması nedeniyle Ege kaynaklarından "hakça" talep etmesi gerekenin de bizatihi Yunanistan olduğu vurgulanmaktadır.

Diğer yandan, konu hakkında Türkiye'nin argümanlarının temeliyse 12 mil uygulamasının yarı-kapalı bir deniz özelliği gösteren Ege Denizi için geçerli olmayacağıdır. Sınırın belirlenmesi hususunda denizlerin coğrafi özellikleri göz önünde tutulmasına dikkat çeken Türkiye, Ege Denizi’nde sahillerin yan yana ve karşı karşıya olması nedeniyle sınırlandırmanın gerekliliğini kabul etmektedir. Türkiye'ye göre, bir devlet karasularının sınırını saptarken, başkasının açık denizle bağlantısını engellemeyecek biçimde davranmalıdır. Ne var ki, 12 mil halinde Türkiye'nin Ege'de açık denizle bağlantısını sınırlanmakta, üstelik Marmara'dan başlayarak Akdeniz'e çıkışı ve Kıbrıs'a erişimi büyük ölçüde güçleştirmektedir. Şu anda, birçok adası nedeniyle, Yunan karasuları Ege Denizi'nin yaklaşık yüzde 40'ını oluşturmaktadır. Ege'de karasularının Yunanistan lehine tek taraflı olarak 12 mile genişletilmesi, Yunanistan'ın karasuları oranını yüzde 70'e yükselmektedir. Böyle bir durumda açık deniz büyüklüğü yüzde 51'den yüzde 19'a düşerken Türkiye'nin karasuları Ege Denizi'nin yüzde 10 'unun altına inmektedir. ${ }^{41}$ Türkiye, karasuları sınırları belirlenirken BMDHS'nin 300. maddesinde yer alan hakkaniyet ilkelerinden yola çıkılmasına özel bir vurgu yapmaktadır. Aşağıdaki haritada görüldüğü üzere aradaki fark Türkiye'nin Ege'de deniz sınırlarının oldukça daralmasına yol açmaktadır.

\footnotetext{
${ }^{41} \mathrm{Bu}$ hesaplamalar aynı zamanda Türkiye'nin karasuları konusunda resmî pozisyonunu yansitmaktadır. "Başlıca Ege Denizi Sorunları", http://www.mfa.gov.tr/baslica-ege-denizisorunlari.tr.mfa, (Erişim Tarihi: 17.05.2020). Başka bir hesaplamaya göre de altı mil uygulamasında \%35 olan Yunan karasuları \%63,9'a çıkmakta; Türkiye için aynı genişlemede karasuları yüzde 8,8 'den yüzde 10 'a yükselmektedir. Uluslararası sular ise \%56'dan \%26,1'e düşmektedir. Alexis Heraclides, Yunanistan ve "Doğudan Gelen Tehlike" Türkiye: Türk -Yunan İliskilerinde Çıkmazlar ve Çözüm Yollar, (Çev. Mihalis Vasilyadis, Herkül Milas), 2. Baskı, İletişim Yayınları, 2003, s. 208.
} 


\section{Harita: 6 ve 12 Mil'e göre Ege'de Karasuları}

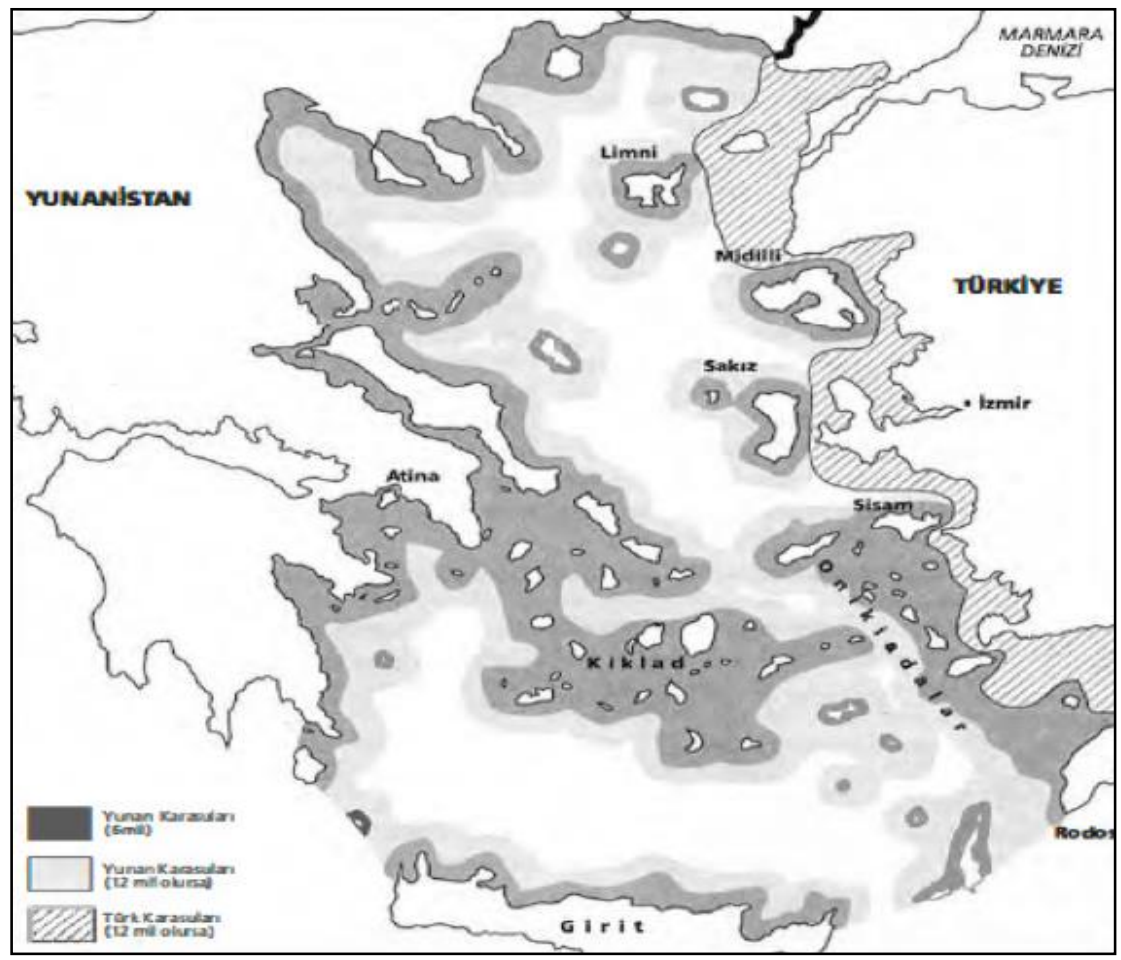

Kaynak: Melek Firat, “1960-1980 Yunanistan’la İlişkiler”,

Baskın Oran (Ed.), Türk Dış Politikası, Kurtuluş Savaşından Bugüne Olgular, Belgeler,

Yorumlar, Cilt 1, 15. Baskı, İletişim Yayınları, İstanbul, 2009, s. 751.

Bu şartlarda Ege'de Yunan adaları ile Anadolu yarımadası arasındaki 2-3 millik kısa mesafeler nedeniyle bir Türk limanından diğerine geçmek açık denizlerden değil, Yunan karasuları üzerinden olabilmektedir. ${ }^{42}$ Yine karasularının genişlemesi durumunda Yunanistan'ın kıta sahanlığı ve ulusal hava sahası da buna bağlı olarak genişleyecektir. Bu durum petrol ve gaz arama faaliyetleri ile deniz ticaretini etkileyeceği gibi Türkiye'nin Ege Denizi üzerinde askerî uçuş ve tatbikatlarını da zora sokacaktır.

\footnotetext{
${ }^{42}$ Şule Kut, a.g.e, s. 516-517.
} 
Çünkü 12 mil karasuları genişliği durumunda Türkiye'nin hak iddia ettiği kıta sahanlığ 1 , Ege'nin toplam deniz yatağ 1 alanına oranla otomatik olarak 16,3 oranından yüzde 9,27 oranına inmektedir. Kıta sahanlığı haklarının, karasuları gibi bir başka hukuksal kavrama ilişkin yeni gelişmelere dayanarak ortadan kalkması Türkiye'ye göre hukuksal bir çelişkidir. Sonuçta haritada yer alan 12 deniz mili üzerinden yapılan ayrım, çıkar dengesini Yunanistan lehine çeviren sonuçlar doğurmaktadır. Başka bir deyişle Yunanistan'ın 12 mil genişlik isteği, Ege'nin en az üçte ikisi üzerinde üstün konumda olması anlamına gelmektedir.

\section{Sonuç}

İki komşu ülke Türkiye ve Yunanistan, dar ve adalarla kaplı Ege Denizi'nde birbirleriyle ilgili sorunların özü olan karasularının sınırlandırılması hususunda hukuki ve siyasi anlaşmazlıklarını yapılan görüşmelere rağmen şimdiye kadar çözüme kavuşturamamıştır. Gelinen aşamada Yunanistan, Türkiye'nin Ege'de karasuları konusunda BMDHS hükümlerine aykırı davrandığı iddiasını sürdürmekte, karasularını 12 mil genişliğine çıkarma hususunu saklı tuttuğu haklar arasında saymaktadır. Buna karşılık Yunanistan'ın Ege Denizi'nde karasularını 6 mil ötesine taşımasının adaletsiz paylaşım olacağını vurgulayan Türkiye ise karasuları sınırları için hakkaniyet prensiplerine göre bir hakkın kötüye kullanılmasının önüne geçileceği bir düzenden yanadır. Bu tezler, geçmişten gelen tarihsel çekişmelerden etkilenmiş her iki devlet yöneticilerinin konuya ekonomik etkenler ile ulusal güvenlik üzerinden bakmaları ulusal çıkar dengesi üzerinden taviz vermeyen politikalara yol açmışır. Her halükârda iki devlet arasındaki görüş ayrılıkları, bir bütün olarak bölgede çıkan diğer yetki tartışmalarına yansıyacak şekilde onların da çözümünü zorlaştıran sonuçlar üretmiştir.

Çalışmada tarafların büyük ölçüde kendine has özelliklere sahip Ege Denizi'nde egemenlik alanlarının belirlenmesi hususundaki sübjektif hukuki ve siyasi tezlerini seyir, uçuş ve bölgedeki kaynakların kullanım durumunu etkileyen karasuları sorunu üzerinden oluşturdukları vurgulanmıştır. Uluslararası hukuka göre bir devletin üzerindeki hava sahası da dâhil olmak üzere tam egemenliğinin olduğu alanlar olan karasularının, deniz yatağı ile toprak altındaki kaynakların arama/tarama, çıkarma ve kullanma hakkının kapsaması söz konusu çekişmeyi önemli kılmaktadır. Dolayısıyla karasuları konusundaki hukuki düzenlemelerin kıta sahanlığı ve münhasır ekonomik bölge gibi diğer deniz yetki alanları hakkındaki kurallar üzerinde de 
belirleyici etkisi bulunmaktadır. Bu çerçevede Yunanistan'ın 1930'lu yıllardan beri Ege'deki karasularının genişliğini sürekli ve kesintisiz biçimde genişletme isteği, Türkiye'nin deniz yetki alanlarında manevra alanının daraltılması arzusunun açı göstergesidir. $\mathrm{Bu}$ durum aynı zamanda Yunanistan'ın Ege'de yetki alanlarını genişleteceğinden nispeten daha geniş olarak Türkiye'nin Doğu Akdeniz'deki potansiyel zenginliklerin aramas1, çıkarılması ve kullanılması hakkını sınırlamayı da kapsayan geniş bir stratejinin parçasını olarak değerlendirilmelidir. $\mathrm{Bu}$ nedenlerle Ege Denizi'nde karasuları sınırlandırılması, her iki ülkenin de yararlanacağı ekonomik ve güvenlik fayda dengesini sağlayacak biçimde kendine has dinamiklerle olabilme ihtimali en makul seçenek olarak durmaktadır.

\section{Summary}

In this study, width of territorial waters in international legal texts, implementation of the rules as its legal regime and limitation on the issue were examined. The study focused on Turkey's foreign policy approach towards the problem and legal and political responses to the arguments of Greece on the international level. As the historical process was shown that Turkey and Greece have been unable to resolve legal and political conflicts over width and limitation of territorial waters of Aegean Sea showing exceptional qualities covered with narrow islands. Since the solution had not been reached, recurrent crises in bilateral relations have emerged since 1970s.

The fact that the rules of both states look at the issues from national security perspective, which has created uncompromising policies over rights and national interest balance. In addition to this, the unilateral expansion of Greece in the Aegean poses a disadvantage for Turkey in terms of delimitation. It is clear that the territorial waters problem in the Aegean Sea is the product of a strategy of Greece, which is to limit Turkey's right of access to resources under the sea as recognized under international law by narrowing Turkey's maritime sovereignty space. Therefore, Turkey should defend places where it has maritime sovereignty by not leading controversy and maintain the principle, which follows international law. 
Ege Denizi’nde Yetki Alanları Paylaşımının Öncülü: Karasuları Sorunu

\title{
Çatışma Beyanı
}

\author{
Araştırmanın yazar olarak herhangi bir çıkar çatışma beyanım \\ bulunmamaktadır.
}

\section{Destek ve Teşekkür Beyanı}

Çalışmanın hazırlanmasında hiçbir dış finansmandan yararlanılmamıştır.

\section{KAYNAKLAR}

Kitaplar

AYMAN, S. Gülden, İyi Komşuluğun Formülü: Türk Dış Politikasında Teritoryal Sorunlar, Yalın Yayıncilık, İstanbul, 2012.

"Negotiations and Deterrence in Asymmetrical Power Situations:

The Turkish-Greek Case", Mustafa Aydin and Kostas Ifantis, Turkish-Greek Relations:

The Security Dilemma in the Aegean, Routledge, London and New York, 2004, ss. 213 243.

BAŞEREN, Sertaç Hami, Ege Sorunları, 2. Baskı, Türk Deniz Araştırmaları Vakfı Yayınları, Ankara, 2006.

FIRAT, Melek, “1960-1980 Yunanistan'la İlişkiler”, Baskın Oran (Ed.), Türk Dış Politikası, Kurtuluş Savaşından Bugüne Olgular, Belgeler, Yorumlar, Cilt 1, 15. Bask1, İletişim Yayınları, İstanbul, 2009. ss. 716-768.

HERACLIDES, Alexis, The Greek-Turkish Conflict in the Aegean: Imagined Enemies, Palgrave Macmillan, New York, 2010.

GÜNER, Serdar Ş., "The Unresolved Aegean Dispute: Problems and Prospects" Alexis Heraclides and Gizem Alioğlu Çakmak (Eds.), Greece and Turkey in Conflict and Cooperation, Routledge, London and New York, 2019,

İNAN, Yuiksel ve Yücel Acer, “The Aegean Disputes”, Foreign Policy Institute, Ankara, 2003,

KUT, Şule, “Türk Dış Politikasında Ege Sorunu”, Faruk Sönmezoğlu (Ed.), Türk Dış Politikası Analizi, Der Yayınları, İstanbul, 2004, s. 507-525.

KURAN, Selami, Uluslararası Deniz Hukuku, 3. Baskı, Türkmen Kitapevi, İstanbul, 2009.

KURUMAHMUT, Ali, Ege'de Temel Sorun: Egemenliği Tartışmalı Adalar, Türk Tarih Kurumu, Ankara, 1998.

ÖZKIRIMLI, Umut ve Sypros A. Sofos, Tarihin Cenderesinde Yunanistan ve Türkiye'de Milliyetçilik, İstanbul Bilgi Üniversitesi Yayınları, İstanbul, 2013.

ÖZMAN, Aydoğan, Deniz Hukuku I: Giriş, Kaynaklar, Kişiler, Nesneler, Ulusal Alanlar, Turhan Kitabevi, Ankara, 2006.

PAZARCI, Hüseyin, Uluslararası Hukuk, Turhan Kitabevi, Ankara, 2009.

SCHRIJVER, Nico, Sovereignty Over Natural Resources: Balancing Rights and Duties, Cambridge, Cambridge University Press, 2008.

TAŞKIRAN, Cemalettin, Oniki Adanın Dünü ve Bugünü, Genel Kurmay ATASE Yayınları, Ankara, 1996. 
TOLUNER, Sevin, Milletlerarası Hukuk Dersleri, İstanbul, Beta Basım Yayın, 1996.

The Law of The Sea: Official Text of the United Nations Convention on the Law of the Sea with Annexes and Index, United Nations, New York, 1983.

\section{Makaleler}

ANLAR Güneş, Şule, "Birleşmiş Milletler Deniz Hukuku Sözleşmesi ve Deniz Çevresinin Korunması", Ankara Üniversitesi Hukuk Fakültesi Dergisi, Cilt 56, Sayı 2 (2007), ss. 1-37.

ARI, Tayyar, "Ege Sorunu ve Türk-Yunan İlişkileri: Son Gelişmeler Işı̆̆ında Karasuları ve Hava Sahası Sorunları", Ankara Universitesi Siyasal Bilgiler Fakültesi Dergisi, Cilt 50, No. 1-2 (Ocak-Haziran 1995), ss. 51-68.

CECCARELLI, Paola, "Naming the Aegean Sea", Mediterranean Historical Review, Vol. 27, No. 1 (June 2012), ss. 25-49.

GÜNER, Serdar Ş., “Aegean Territorial Waters Conflict: An Evolutionary Narrative”, Conflict Management and Peace Science, Vol. 21, No. 4 (September 2004), ss. 297-312.

İNALCIK, Halil, "Helenizm, Megali İdea ve Türkiye”, Doğu Batı, Sayı 31 (Şubat, Mart, Nisan 2005), ss. 9-26.

OXMAN, H. Bernard., "Applying the Law of the Sea in the Aegean Sea", Bayram Öztürk and Nesrin Algan (Eds.), Proceedings of the International Symposium on the Problems of Regional Seas (Turkish Marine Research Foundation-TÜDAV, İstanbulTurkey, 12-14 May 2001), ss. 266-80.

ÖZKIRIMLI, Umut ve Sypros A. Sofos, Tarihin Cenderesinde Yunanistan ve Türkiye'de Milliyetçilik, İstanbul Bilgi Üniversitesi Yayınları, İstanbul, 2013.

ÖZMAN, Aydoğan, "Ege'de Karasuları Sorunu", Ankara Üniversitesi Siyasal Bilgiler Fakültesi Dergisi, Cilt 63, No. 3-4 (Temmuz-Aralık 1988), ss. 173-194.

Internet Kaynakları

"Aegean Sea", https://www.britannica.com/place/Aegean-Sea (Erişim Tarihi: 07.05.2020).

"Başlıca Ege Denizi Sorunları", http://www.mfa.gov.tr/baslica-ege-denizi-sorunlari.tr.mfa, (Erişim Tarihi: 17.05.2020).

"Guidelines for the Prevention of Accidents and Incidents on the High Seas and International Airspace”, http://www.mfa.gov.tr/site_media/html/aegean-sea-referencedocuments-2.pdf (Erişim Tarihi: 18.09.2020).

http://www.mevzuat.gov.tr/MevzuatMetin/1.5.2674.pdf (Erişim Tarihi: 18.05.2020).

https://www.tbmm.gov.tr/tutanaklar/KANUNLAR_KARARLAR/kanuntbmmc047/ka nuntbmmc047/kanuntbmmc04700476.pdf, (Erişim Tarihi:18.05.2020).

Memorandum of Understanding", http://www.mfa.gov.tr/site_media/html/aegean-seareference-documents-1.pdf (Erişim Tarihi: 18.09.2020).

"Yunanistan Başbakanı Çipras: Karasularımızı 6 milden 12 mile çıkaracağız", https://tr.euronews.com/2018/11/09/yunanistan-basbakan-cipras-karasularimizi-6milden-12-mile-cikaracagiz (Erişim Tarihi: 16.05.2020). 